\title{
Utilization of brewers dried grains (BDG) in growing-finishing pigs
}

\author{
P. QUEMERE, R. FOURDRINIER *, A. LEFRANC **, F. WILLEQUET \\ Société d'Etude régionale sur l'Elevage du Porc, Institut supérieur agricole, \\ 60026 Beauvais \\ *E.D.E., 140, boulevard de la Liberté, B.P. 1177, 59000 Lille \\ **I.T.P., région Nord, 27, route de Bapaume, Le Transloy, 62450 Bapaume \\ France
}

Valorization of brewers grain by the pig has not been much investigated. For that reason, it seemed interesting to test its possible use in pig feeding in a region where it is currently fed to cattle. The trial was made on 168 pigs distributed into groups at a mean live weight of $23.6 \mathrm{~kg}$. Three diets containing 0,10 and $20 \mathrm{p}$. 100 BDG were compared. They were formulated to supply $2.55 \mathrm{~g}$ lysine $/ 1000 \mathrm{~kg} \mathrm{DE}$.

The daily levels of feed intake were similar whatever the diet. The animals did not counterbalance the reduced energy concentration of the diet containing BDG by an increased feed intake. The energy intake was therefore reduced by 3 and 8 p. 100 with diets II and III, respectively. The growth of boars decreased almost linearly with the level of incorporation ( -5 p. 100 and -11 p. 100, respectively). Females were more affected (-18 p. 100 at the highest level of incorporation). During the finishing period, the growth of boars was no more affected even with diet III (20 p. 100), that of the females was not affected with diet II $(10 \mathrm{p} .100)$, while it was reduced with diets III ( $-7 \mathrm{p}$. 100).

There was a non-linear increase in the feed conversion ratio with the level of BDG : i.e., +7 p. 100 and 18 p. 100 , respectively during the growing period. This trend was less marked during the finishing period. Incorporation of cellulose (BDG) into the diet reduced the commercial yield, especially that of females fed the 20 p. 100 BDG diet. The carcass grading index was reduced by the use of brewers grain parallel to the decrease in the muscle percentage.

From a technical point of view, brewers dried barley grains can be incorporated at the level of 10 p. 100 into finishing diets without problems. However, on account of the present raw matter prices its utilization is not recommended.

\section{Possibilities of improving the feeding value of winter peas in the bacon pig Effect of cooking-extrusion treatment, of storage length and of tryptophan supplementation}

\author{
F. GROSJEAN, J. CASTAING * \\ I.T.C.F., 8, avenue du Président-Wilson, 75116 Paris \\ * A.G.P.M., 122, boulevard Tourasse, 64000 Pau \\ France
}

In a first trial made on a group of 96 minimal disease Large White pigs we compared a control diet based on maize and soyabean meal with two diets including 30 p. 100 winter peas, either raw or extruded. All the diets were offered in the form of moistened meal. Incorporation of a high level of peas led to a decrease in animal performance especially during the growing period. Extrusion by destroying most of the antinutritional factors led to an improvement in performance as compared to those obtained with the diet including raw peas. However, this improvement was limited since there remained a discrepancy of 3.5 p. 100 between the feed conversion ratios of the diet including extruded peas and the control diet. 
In a second trial we compared a control diet (maize-soyabean meal) with a diet containing 36 p. 100 peas stored for one year and with two diets containing 36 p. 100 peas of the last crop supplemented or not with tryptophan. Storage of peas did not change its feeding value since the nutritional characteristics remained constant. Supplementation with tryptophan increased the animal performance. During the growing period the feed efficiency of the supplemented diet was improved by 7 p. 100 as compared to the nonsupplemented diet, but remained 11 p. 100 lower than that of the control diet. During the finishing period it was $5 \mathrm{p} .100$ higher than that of the non supplemented diet and was equal to that of the control diet.

\title{
Utilization of spring peas associated with wheat or maize in bacon pig diets
}

\author{
F. GROSJEAN, J. CASTAING * \\ I.T.C.F., 8, avenue du Président-Wilson, 75116 Paris \\ A.G.P.M., 122, boulevard Tourasse, 64000 Pau \\ France
}

The purpose of the present study was to determine the maximum level of incorporation of spring peas into bacon pig diets, while that of winter peas is already well-known (15 p. 100).

In a first trial made on a group of 180 minimal disease Large White pigs, we compared, according to a factorial design, performance of animals receiving 0,15 or 30 p. 100 peas in a simple diet based on maize or wheat supplemented with soyabean meal. In a second trial made on a group of 96 minimal disease Large White pigs we studied the total replacement of soyabean meal by 37 p. 100 spring peas supplemented or not with industrial lysine. We compared these two diets to a control diet without peas and to a diet containing 30 p. 100 peas.

Both trials showed that it was possible to incorporate $30 \mathrm{p} .100$ spring peas into bacon pig diets without reducing the performance over the whole fattening period despite a slight decrease in growth between 25 and $60 \mathrm{~kg}$. Incorporation of peas did not reduce the carcass yield and body composition. Its effect on growth and carcass quality was identical whatever the basal cereal used (maize or wheat).

The second trial showed that total replacement of soyabean meal by peas led to a reduction in the performance which was only very slightly compensated by the lysine supplementation.

\section{Utilization of cereals in simple diets for weaned piglets Comparison of two physical forms : meal and pellets}

\author{
J. FEKETE, J. CASTAING*, O. LAVOREL, M. LEUILLET \\ I.T.C.F., 8, avenue du Président-Wilson, 75116 Paris \\ * A.G.P.M., 122, boulevard Tourasse, 64000 Pau \\ France
}

Six trials were made with 2832 piglets in the same conditions and in two experimental stations with the aim of comparing the performance of piglets fed a cereal-based diet (maize, wheat, barley) offered in two different physical forms : meal or pellets. The incorporation levels of cereals varied from 54 to 64 p. 100 . 